\title{
Effect of organic amendment on chronically hydrocarbon contaminated soil after chemical remediation
}

Rocio Medina1; Natalia Di Clemente'; Verónica Mora'; Janina Alejandra Rosso²; María Teresa Del Panno'

1. Centro de Investigación y Desarrollo en Fermentaciones Industriales (CINDEFI). 2. Instituto de Investigaciones Fisicoquímicas Teóricas y Aplicadas

\section{INTRODUCTION}

Polycyclic aromatic hydrocarbons (PAHs) are hydrophobic organic pollutants persistent in soil[1,2]. The remediation using chemical oxidants could overcome the limitations of bioremediation in the PAHs elimination ${ }^{[3]}$, although it could also damage the community and the soil structure ${ }^{[4,5]}$.

The aim of this work was to evaluate the early effect of a combined strategy applied to chronically PAHs-contaminated soil.

\section{MATERIALS AND METHODS}

Chronically contaminated soil was sampled from a petrochemical industry near La Plata city ${ }^{[6]}$. The original hydrocarbons content was 214 ppm of PAHs (1 \% bioavailable) and 2400 ppm of aliphatic hydrocarbons.

Microcosms were monitored once a week along 28 days, by count of heterotrophic on R2 agar; most probably number (MPN) of PAHs hydrocarbons degrading bacteria (DB) on liquid mineral medium supplemented with PAHs, phosphorous solubilizing bacterial (PSB) and fungi on rose bengal medium. Dehydrogenase activity was measurement during the same period of time ${ }^{[7]}$. At the end of the treatments the hydrocarbons content and aqueous phytotoxic effect on Lactuca sativa were evaluated ${ }^{[8]}$. Finally, structure of bacterial community was studied by pyrosequencing of $\mathrm{V} 1-\mathrm{V} 3$ regions of $16 \mathrm{~S}$ rRNA ${ }^{[6]}$.

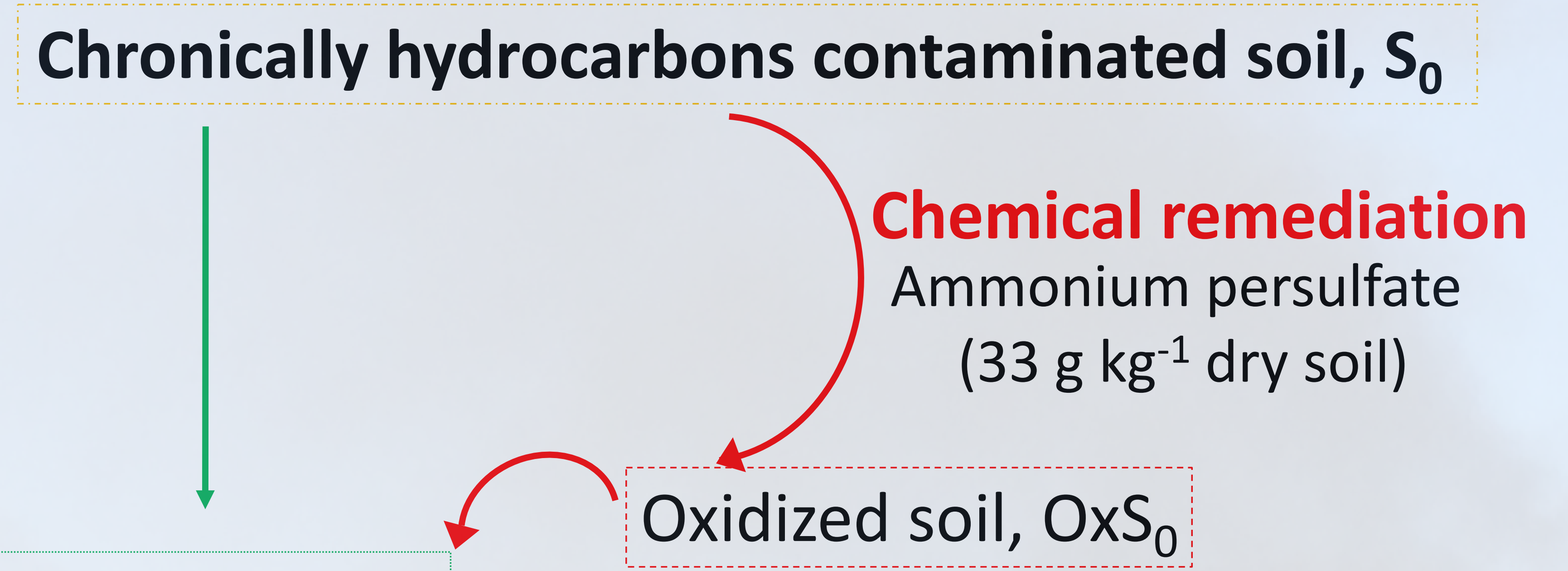

Bioremediation

Stimulated microcosms: Compost addition ( $7 \mathrm{~g}$ dry soil:

3 g dry mature compost).

Unamendement microcosms

Moisture content $(20 \%), 25^{\circ} \mathrm{C}$. Moisture content $(40 \%), 25^{\circ} \mathrm{C}$
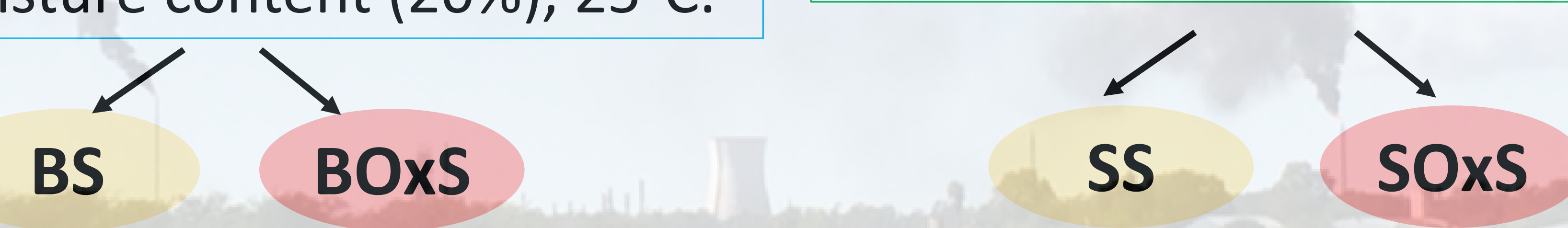

\section{RESULTS}

\section{PAHs elimination}

Oxidative treatment: Elimination of $29 \%$. Stimulation with compost: Additional elimination of $20 \%$.

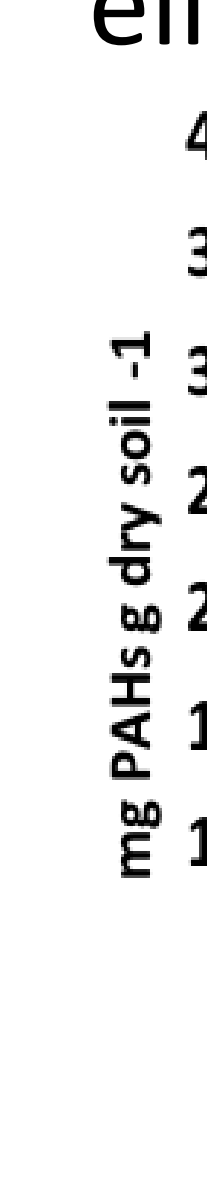

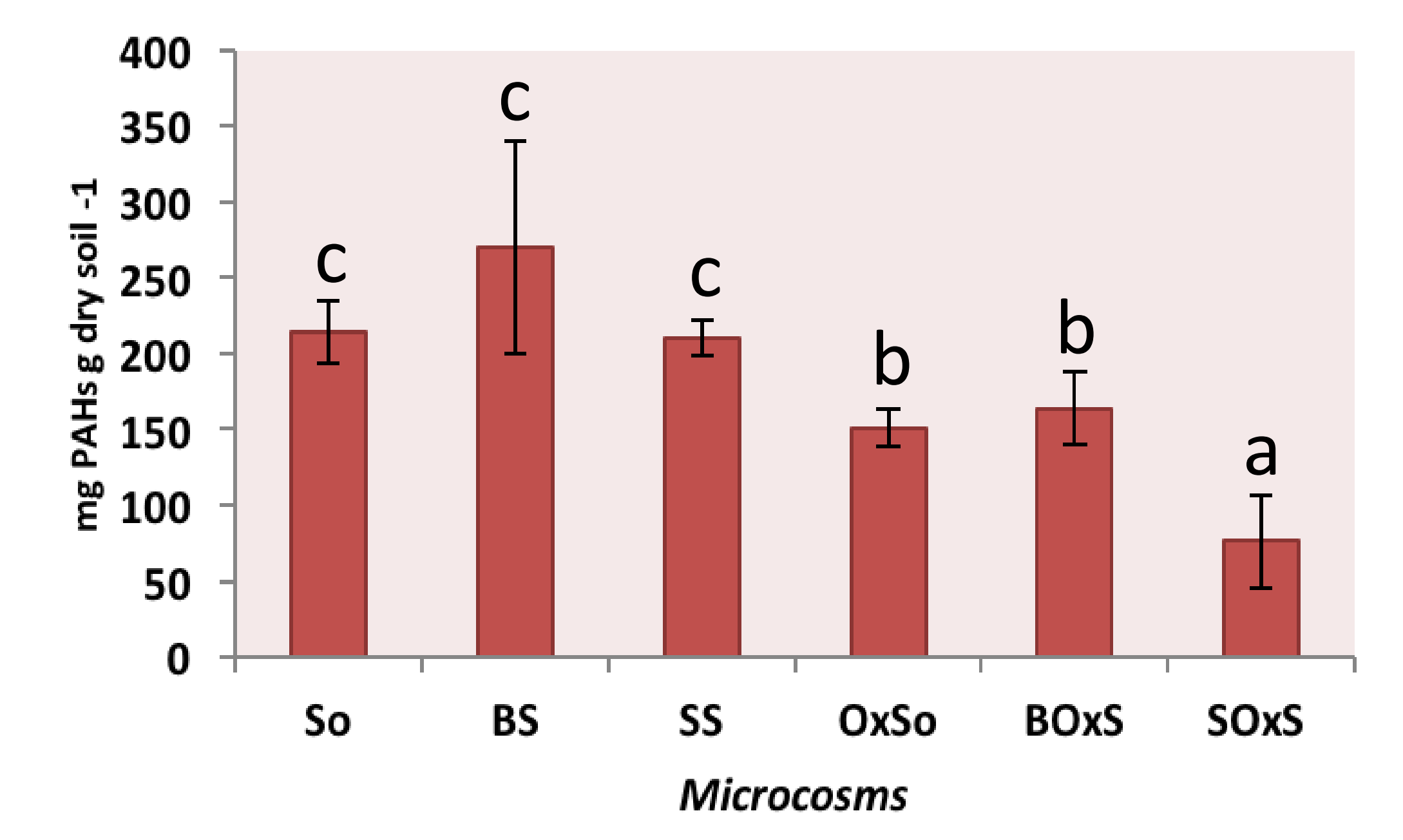

Dehydrogenase activity $\mathrm{S}_{0}$ and $\mathrm{OxS}_{0}$ : not detected.

Stimulation with compost: increases on global soil activity.
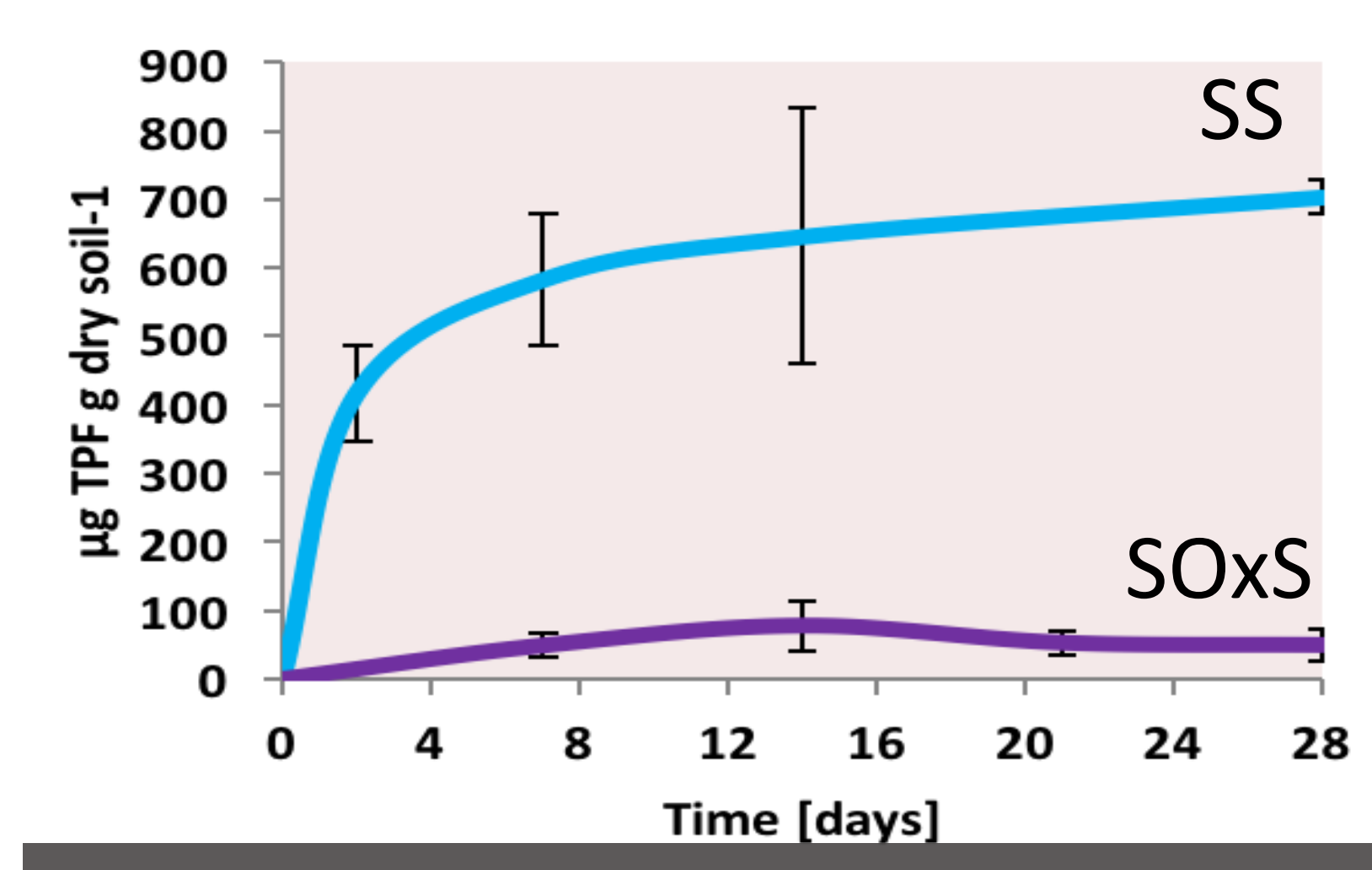

\section{Aqueous extracts toxicity}

PS addition and stimulation with A dramatic decline of the cultivable populations was observed mature compost increases inhibition immediately after chemical remediation.

germination index and elongation Stimulation with mature compost inhibition index.

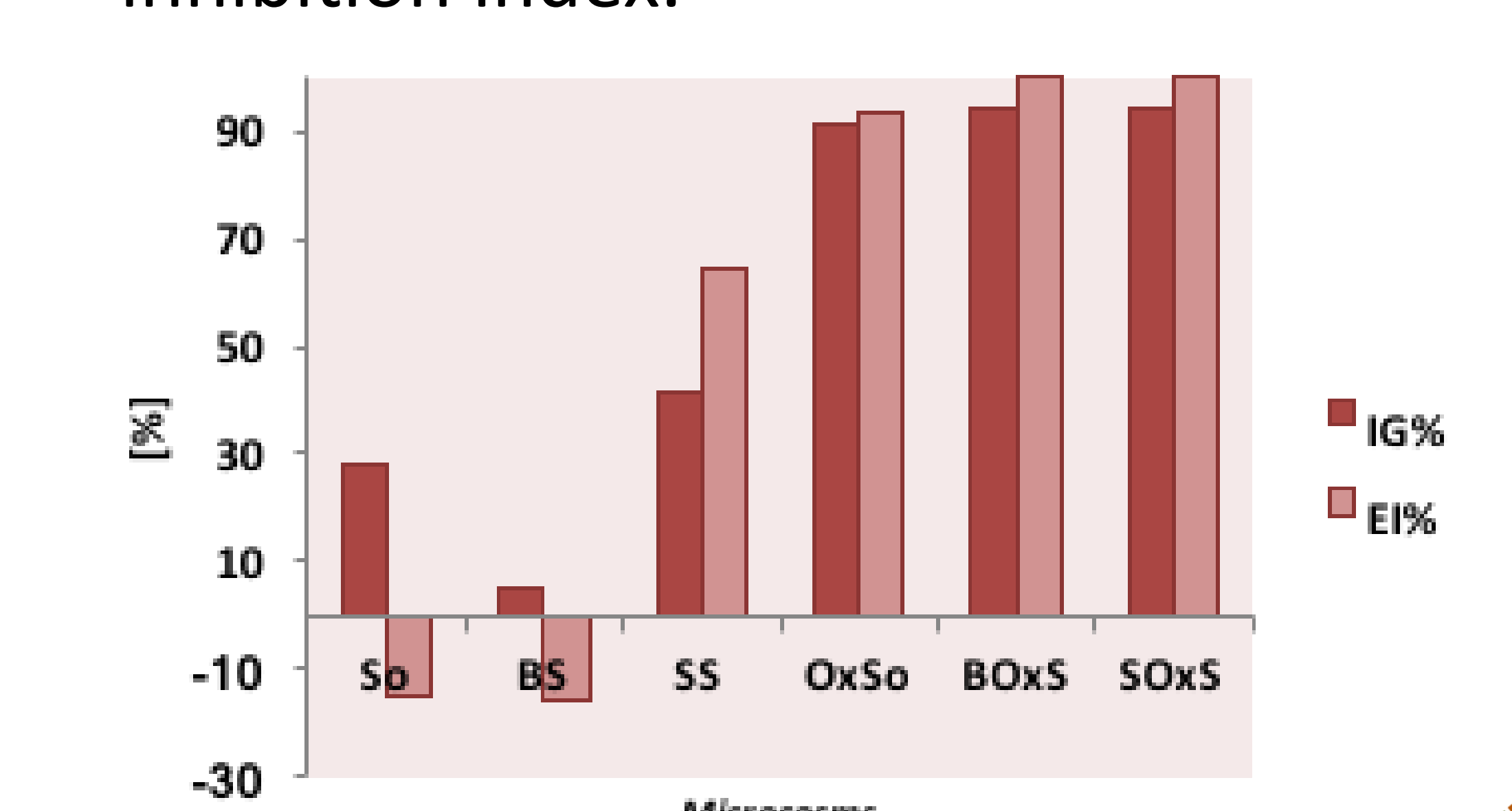

allowed the cultivable population recovery.

\begin{tabular}{|c|c|c|c|c|}
\hline & $\begin{array}{c}\log \mathrm{CFU} / \\
\mathrm{g} d \mathrm{ds}\end{array}$ & $\begin{array}{c}\text { Log PSB / } \\
\text { gds }\end{array}$ & $\begin{array}{c}\text { Log CFU Fungi / } \\
\mathrm{g}^{-1} \mathrm{ds}\end{array}$ & $\begin{array}{c}\text { Log MPN-PAHs DB / } \\
g^{-1} \mathrm{ds}\end{array}$ \\
\hline $\mathrm{S}_{0}$ & 7.6 & 3.7 & 5.7 & 3.4 \\
\hline BS & 7.6 & 5.0 & 4.7 & 2.6 \\
\hline SS & 7.5 & 6.2 & 5.6 & 3.9 \\
\hline $\mathrm{OxS}_{0}$ & 4.3 & nd & 4.0 & 1.9 \\
\hline BOxS & 7.6 & 4.4 & 3.9 & 2.2 \\
\hline SOXS & 7.8 & 6.4 & 5.2 & 3.4 \\
\hline
\end{tabular}

Community structure

Structure and diversity indexes of the bacterial community was recovered after 28 days.

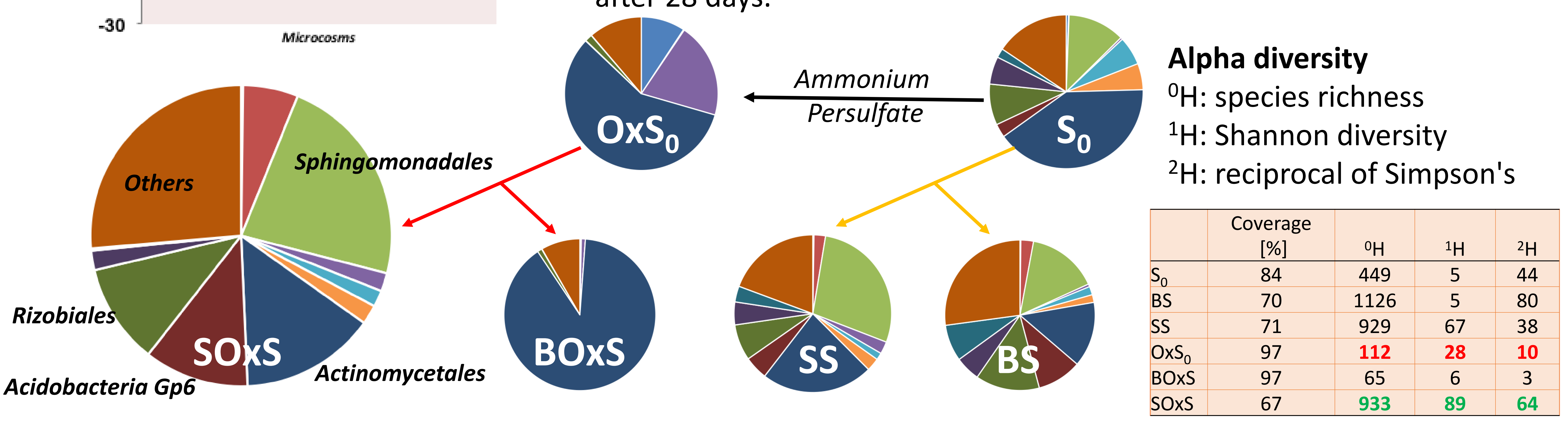

CONCLUSIONS

The combined treatment allowed increases PAHs elimination, recovering cultivable bacterial and fungal populations and consequent dehydrogenase activity.

Toxicity was not reverted after PS addition neither mature compost addition, probable due to high residual salinity.

$>$ After 28 days of mature compost addition the diversity indices and bacterial community structure were recovery.

Members of Sphingomonadales, Actinomycetales, Acidobacteria Gp6 and Rizobiales orders were predominant, suggesting the active metabolism of organic matter, nutrients mobilization and hydrocarbons degradation.

A longer term treatment could define the potentiality of the combined strategy for the elimination of PAH.

References: [1]. Yen et al. 2011. Journal of Hazardous Materials 186 (2): 2097-2102. [2]. Szczepaniak et al. 2016. Environmental Science and Pollution Research 23 (22): 23043-56. [3]. Lim et al. 2016. Marine Pollution Bulletin 109 (1). Elsevier Ltd: 14-45. [4]. Sutton et al. 2011. Journal of Soils and Sediments 11 (1): 129-40. [5]. Mora et al. 2014. Environmental Science and Pollution Research 21 (12): 7548-56. [6]. Medina et al. 2018. Science of The Total Environment 618, 518-530. [7]. Del Panno et al. 2005. FEMS Microbiology Ecology 53 (2): 305-16. [8]. Sobrero et al. 2004. In Ensayos Toxicológicos Y Métodos de Evaluación de Calidad de Aguas., 55-68. 